\title{
Should I Leave This Industry? The Role of Stress and Negative Emotions in Response to an Industry Negative Work Event
}

\section{Introduction}

In response to the COVID-19 pandemic, the majority of American states and cities issued workplace restrictions, such as "shelter-in-place" or "stay-at-home" orders, to prevent the spread of the disease. While these workplace restrictions varied in start date, duration, and scope, most businesses not considered "essential" were required to physically close their spaces and continue their operations remotely. The COVID-19 pandemic is an example of a negative work event that impacts entire industries; the impact, however, was not equal across industries (US Department of Labor, 2020). Instead, the COVID-19 pandemic has put a spotlight on the flexibility of some industries and the vulnerability of others. For example, employment rates in the wholesale trade, transportation and warehousing, information, and financial industries, changed little over the months following workplace restrictions (US Department of Labor, 2020).

The hospitality industry, in contrast, was greatly affected because typical operations in this industry, like meetings, events, hotels, and restaurants, had to close their spaces. The US Department of Labor (2020) reported that the hospitality industry, particularly the hotel and restaurant sectors, accounted for two-thirds of the jobs lost in March of 2020, during the height of the workplace restrictions orders. The American Hotel and Lodging Association (2020) reported that $70 \%$ (roughly 3.7 million) of the direct hotel industry workforce were laid off or furloughed and the National Restaurant Association (2020) reported that 7 out of 10 restaurants laid off their employees, resulting in over 8 million restaurant employees laid off as a result of the COVID-19 pandemic. 
The COVID-19 pandemic is not the only example of negative work events that impact industries differently. For example, 9/11 had a greater negative impact on the airline, tourism, and insurance industries than others (Makinen, 2002). The Great Recession also had a greater impact on financial services and construction industries relative to other industries (Barello, 2014). These examples underscore the importance of examining how employees react to negative industry-related events, because negative events can be stressful and emotional, potentially leading to negative attitudes and behaviors toward their industry.

Thus, the primary objective of this research is to examine the effect of subjective stress on employee negative emotions in response to a negative work event that impacts their industry, such as the hospitality industry, and understand how employees react to stress and negative emotions through subsequent attitudes and behaviors toward the industry. Although the effects of stress and negative emotions on work attitudes have been theorized and widely researched (e.g., Lee \& Ashforth,1996; Podsakoff et al., 2007; Spector \& Goh 2001; Weiss \& Beal, 2005), there are two major limitations: 1) organization-specific work events and 2) organization-specific attitudes and behaviors. First, the majority of this literature has focused on organization-specific work events rather than industry-specific work events (e.g., Brown et al., 2005; Pindek et al., 2019). For example, organization-specific negative events related to employee stress and/or negative emotions include pressures to work when sick (Arjona-Fuentes et al., 2019), organizational work demands (Ariza-Montes et al., 2019), workplace bullying (Jung \& Yoon, 2018), sexual harassment (Madera, 2018), abusive supervision (Park \& Kim, 2019), and customer mistreatment (Lee et al., 2020). On the other hand, examining industry-specific work events like 9/11 and the Great Recession could shed light on how an event can impact employees of an entire industry. 
The second major limitation to this literature is that research has mainly focused on organization-specific attitudes and behaviors in response to negative work events (Morgeson et al., 2015). For example, research examining hostile work environments (i.e., organizationspecific negative events), such as bullying and harassment, have focused on measuring employee negative attitudes and behaviors toward their organization, such as blaming the organization, service sabotage, and counterproductive behavior, while neglecting attitudes and behaviors toward the hospitality industry (e.g., Jung \& Yoon, 2018; Lee et al., 2020; Madera, 2018, Park \& Kim, 2019). In addition to the staggering turnover rates of the hospitality industry, recent workforce projections point to a potential thinning future employees and leaders (Baum, 2019). Thus, the first underlying research question of this study is if the COVID-19 pandemic, a negative work event that severely impacted the hospitality industry as a whole, can negatively influence employees' stress and negative emotions. The second underlying research question is if the stress and negative emotions associated with COVID-19 relates to attitudes and behaviors toward the industry.

These are unfortunate gaps in the literature because industries, like the hospitality industry, often rely on a pipeline of professionals who have the knowledge, skills, and abilities (KSAOs) that are industry-specific and transferable across organizations within an industry (Baum, 2019; Garavan, 2012; Bowen \& Ford, 2002; Whysall et al., 2019). These industries may suffer from significant talent loss if industry-related negative work events negatively influence their attitudes and behaviors toward the industry. For example, in a study of human resource strategies in the information technology industry, Ang and Slaughter (2004) showed that many organizations adopt strategies to manage their internal human capital that focuses on KSAOs that are industry-specific rather than organization-specific. Research also shows that industry-specific 
unemployment rates can influence employee turnover at the individual level, suggesting that employees look to industry-related events when making decisions about quitting (Schmidt et al., 2018).

Therefore, the purpose of the current paper was to understand the impact of COVID-19 on attitudes and behaviors toward the hospitality industry using a mixed-methods approach. The current research draws from the event system theory (Morgeson et al., 2015) and Spector and Goh's (2001) model of occupational stress. In Study 1, an exploratory qualitative study provides evidence that the COVID-19 pandemic is perceived as a negative event affecting the industry, rather than only affecting a job or a particular company. Additionally, employees perceive a negative event, like the COVID-19 pandemic, to be a stressor, leading to feeling subjective stress and negative emotions related to working in the industry. In Study 2, a quantitative study examined the impact of COVID-19 using current employees in the hospitality industry by testing a model in which subjective stress and negative emotions associated with COVID-19 relates to attitudes and behaviors toward the industry.

---Insert Figure 1 here---

\section{Conceptual model and hypotheses development}

The conceptual model guiding our paper is illustrated in Figure 1. The model draws from the event system theory (Morgeson et al., 2015), which posits that major negative events, such as pandemics or terrorist attacks, can affect employees directly, including attitudes and behaviors toward their organization. Although the event system theory (Morgeson et al., 2015) limits process to organization-specific attitudes and behavior, we build on this theory by examining how negative events, like COVID-19, can lead to negative attitudes and behaviors toward their industry. To explain this process - the links between COVID-19 and negative attitudes and 
behaviors toward an industry — the current model was guided by Spector and Goh's (2001) model of occupational stress, which distinguishes objective environmental stressors, such as the COVID-19 pandemic, and its appraised or perceived subjective stress. Therefore, based on Spector and Goh's (2001) model of occupational stress, layoffs, furloughs, and subsequent negative work events or consequences of containing COVID-19 and the pandemic are defined as objective environmental stressors. As a result, these negative work events (e.g., layoffs, furloughs, working as an essential business employee through a pandemic) result in subjective appraisals and stress. Whereas the COVID-19 pandemic is construed as an objective environmental stressor, how individual employees appraise this negative work event and subjectively process the successive stress is conceptualized as subjective stress in the proposed model. The current conceptual model shows that among employees, a negative work event that impacts their industry is a stressor that elicits subjective stress, relating to negative emotions.

Negative emotions, in turn, motivate individuals to assess the situation (e.g., its implications for their well-being) and respond in a way to address it (Lazarus \& Folkman, 1984) often resulting in job strains (Spector \& Goh, 2001), which are negative reactions to a work stressor and can manifest as psychological (e.g., negative work attitudes) or behavioral (e.g., counter-productive behaviors) (Pindek et al., 2019). Particularly for industries impacted by work events, this process can lead employees to develop negative attitudes and behaviors toward their industry, such as industry turnover intentions, defined as an employee's willingness to leave an industry (Tongchaiprasit, \& Ariyabuddhiphongs, 2016) and industry negative word-of-mouth, defined as the communication of personal experiences with an industry (Karabas, Joireman, \& Kim, 2019). In other words, as a way to deal with the stress and negative emotions, employees might direct their emotions and behaviors toward leaving or staying in their industry. Therefore, 
the current paper builds on Spector and Goh's (2001) model of occupational stress by examining attitudes and behaviors toward an industry as opposed to limiting these effects to an organization. In addition, Spector and Goh's (2001) model of occupational stress limits the effects of stress to organization-related events, therefore, by examining COVID-19 as the source of the subjective stress and negative emotions, the current study extends Spector and Goh's (2001) model to include major negative events, such as a pandemic.

\subsection{Hospitality industry as a context}

The hospitality industry is an ideal industry to examine how a negative work event that impacts an industry could influence employees' negative attitudes and behaviors toward the industry. The hospitality industry, particularly hotels and restaurants, supports over 23 million jobs in the US (American Hotel and Lodging Association, 2020; National Statistics, 2019). While the hospitality industry provides a vast number of jobs, the characteristics of the industry stimulate a unique demand for hospitality education and programs. The hospitality industry calls for employees fluent in their operational knowledge and ability to integrate new technology and trends as well as the interpersonal skills necessary to meet the changing and growing demands of customers and customer service (Baum, 2019; Brown et al., 2015). Therefore, the hospitality industry has established a cooperative and mutually beneficial relationship with hospitality university programs and majors where the industry creates a need for talent and skills, and university programs provide talented individuals (Baum, 2019). Thus, industries, like the hospitality industry, rely on a loyal workforce who have industry-specific KSAOs.

Coupled with the previous points, employees also form attitudes towards the hospitality industry (Dawson, 2014). Some industries, like the hospitality industry, deliver intangible products (e.g., service experience) that rely on employees' attitudes toward the organization and 
the industry (Bowen \& Ford, 2002; Combs, Liu, Hall, \& Ketchen, 2006). It is often hospitality employees' attitudes and behaviors that signal to customers an organization's mission and vision in terms of customer service, contributing to the success of an organization and the industry (Golubovskaya, Solnet, \& Robinson, 2019). Thus, the hospitality industry relies on (1) a loyal workforce that has industry-specific KSAOs and (2) employees whose attitudes toward the industry affect the production of service.

\subsection{Stress and negative emotions}

Our research adopts Spector and Goh's (2001) conceptualization of job stress to be a circumstance or condition (i.e., stressors) that elicits subjective stress and subsequent feelings of distress (i.e., negative emotions). Stressors are subjective in nature, as the situation does not rise to a stress unless the person perceives it as such, and thus responds emotionally. Subjective stress can also vary by intensity and frequency. Subjective stress stemming from stressors such as workload can be low in intensity, high in frequency (i.e., trivial environmental stress that occurs more workdays than not) and cause minor distress, while subjective stress stemming from acute stressors (i.e., highly intense stressor that occurs once in a while) can result in intense emotional reactions and distress from a single instance (Spector \& Goh, 2001).

Aligned with previous research, negative emotions are immediate reactions to stressful work events and its subjective stress appraisal (Pindek et al., 2019; Weiss \& Beal, 2005). Although there is a range of negative emotions an individual can experience in response to subjective stress, major events and stressors (e.g., a pandemic, terrorist attack, recession) are prone to more subjective stress and thereby inciting a variety of complex emotions. Although discrete negative emotions have been measured empirically and theoretically, the argument for the co-occurrence of general negative emotions as a higher order factor has been made over a 
single, discrete emotion (Fida et al., 2015). For instance, if an employee is fired, the employee is likely to experience a variety of negative emotions like anger towards employer, sadness in losing a job, and fear of unemployment. Therefore, the acute stressor supports the notion of experiencing many heightened and complex negative emotions simultaneously as an immediate response to the subjective stress one feels rather than a singular negative emotion.

The COVID-19 pandemic has resulted in the closing of businesses, furlough, and layoff of employees, changes in business models and operations as well as countless other circumstances and conditions that have resulted in stress among employees. The subsequent changes in policies and procedures resulting from the COVID-19 pandemic are unprecedented and unparalleled, serving as an extreme and unique example of an acute stressor. Thus, the COVID-19 pandemic is likely to be associated with subjective stress and feeling negative emotions for employees working in an industry that was particularly negatively impacted by it.

\subsection{Effects on attitudes and behaviors toward the industry}

In their seminal paper, Lazarus and Folkman (1984) described the relationship between stress and emotions as a process in which individuals change what they think and do when dealing with stress provoking events. Negative emotions, as a response to stress, is often a response to a threat that can harm individuals' well-being and motivates individuals to assess the situation in regard to their well-being (Mogg et al., 2000). Accordingly, emotions motivate individuals to appraise the stressful event and react in ways that would address the aroused stress one feels (Lazarus \& Folkman, 1984), often resulting in job strains (Spector \& Goh, 2001). Job strains are negative reactions to a work stressor and its appraised subjective stress, which can manifest as psychological (e.g., negative work attitudes) or behavioral (e.g., counter-productive behaviors) (Pindek et al., 2019). Therefore, the process, from subjective stress to negative 
emotions, can lead employees to develop negative attitudes and behaviors toward their industry as a reaction to the stress and negative emotions they feel (Spector \& Goh, 2001). In the current study, we conceptualize industry turnover intentions as a psychological strain response and industry negative word-of-mouth as a behavioral strain response to the stress and negative emotions associated with the COVID-19 pandemic.

Turnover intention is an attitude conceptualized as a psychological strain response to stressors at work because turnover intentions are a plan to behaviorally withdraw from a situation that is distressful (e.g., Geurts et al., 1999; Staufenbiel \& König, 2010). Spector and Goh (2001) argued that an employee feeling negative emotions as a result of a stressful event at work might think of a plan to respond, such as leaving. Turnover intentions or intentions to quit is often conceptualized as an organization-related attitude (Podsakoff et al., 2007). The literature shows that when employees experience stress, particularly stressors that inhibit their goals at work, they are likely to feel dissatisfied and subsequently, evoke turnover intentions (Alarcon, 2011; Fried et al., 2008; Podsakoff et al., 2007). Employees dealing with a stressful event that has a negative impact on their industry, such as COVID-19, can also elicit turnover intentions but with their industry as the target of this attitude. In the current study, we propose that employees can also have intentions to quit working in an industry as a way to respond to negative events that have negative impacts on the industry they work in. Research from the hospitality industry shows that employees from this industry do indeed leave not only their organization, but the industry as a place for employment when they cannot cope with the stressors related to this industry, such as the atypical hours, lack of family-friendly schedules, and the 24-hour nature of the business (Blomme et al., 2010; Brown et al., 2015). 
Another way employees can respond to stress at work is through verbally expressing one's negative feelings by telling them to others, which is a behavioral strain response to stress (Day \& Livingstone, 2001; Spector \& Goh, 2001). Specifically, research shows that negative word-of-mouth is interpersonal communication with a focus on negative information about an organization, that can be through personal or social media communication, and is a reaction to negative events that provoke stress and negative emotions (Balaji et al., 2016; Berger, 2014; Field \& Chelliah, 2012; Laczniak et al., 2001; Wetzer et al., 2007). For example, employees can make disparaging comments about their organization when they feel they are the target of workplace injustice (Harris \& Ogbonna, 2013).

Given how the hospitality industry is the industry that has experienced the majority of furloughs and unemployment (US Department of Labor, 2020), employees in this industry are likely to experience subjective stress. As suggested by our proposed model, subjective stress relates to negative emotions, which in turn, motivates individuals to assess the situation. Additionally, Perrewé and Zellars (1999) reviewed cognitive appraisal theory of emotions (Lazarus \& Folkman, 1984) and theory of attribution and emotion (Weiner, 1995) and proposed a causal relationship between subjective stress and emotions. Lazarus (1993) suggested that an individual will first engage in a primary appraisal of the a source of stress by evaluation its motivational relevance (i.e., whether the work is perceived as a stake in the outcome of performance) and motivational incongruence (i.e., whether the work exceeds his/her capabilities) to determine whether he/she will perceive psychological stress. Then, based on Weiner's (1985) theory of motivation and emotion, the individual will search for the causes of felt stress (i.e., internal and external causes) as a means to better control the environment and generate different emotions based on the attributions of the stress. For example, individuals may feel different types 
of negative emotion depending on whether the stress is attributed to internal causes (e.g., lack of efforts and ability) or external causes (e.g., unreasonable demands, task difficulty, lack of resources, and bad luck). Thus, Perrewé and Zellars (1999) proposed that there is a cognitive attribution mechanism underlying the casual relationship between subjective stress and the affective responses (emotions). Then individuals' different affective responses will determine their secondary appraisal coping choices (i.e., problem-solving and emotional-focused coping strategies).

Therefore, Perrewé and Zellars's (1993) framework articulates the mediating role of emotions between primary appraisal (subjective stress) and secondary appraisal (coping choices). Similarly, we argue the pandemic's negative work events are subjectively perceived as stress by employees and evokes an emotional reaction - negative emotions through an attribution process and lead to different psychological and behavioral strain responses. Specifically, our hypothesized model posits that this process can lead employees to direct their emotions and behaviors toward leaving the industry and engage in negative word-of-mouth as psychological and behavioral strain responses. Thus, negative emotions serve as a mediator of the relationship between subjective stress and industry turnover intention as well as between subjective stress and industry negative word-of-mouth. Based on our proposed model, we hypothesized:

H1: Subjective stress is positively related to negative emotions.

$\mathrm{H} 2$ : Negative emotions mediate the relationship between subjective stress and industry turnover intention.

H3: Negative emotions mediate the relationship between subjective stress and industry negative word-of-mouth.

\section{Study 1 methodology}




\subsection{Research design and data collection}

We conducted a qualitative study that analyzed written responses to open-ended questions obtained from 75 current hospitality employees using an alumni network. An alumni network from a hospitality program was used because it ensured that the participants were working in the hospitality industry, had experiences working in hospitality, and due to their college education, had the ability to leave the industry and work in other industries. Due to the constraints by the COVID-19 quarantine, the questions were completed online sent via an email. The qualitative study was guided by the first path of the conceptual model (see Figure 1) to provide evidence that the COVID-19 pandemic is a stressor affecting the hospitality industry and is associated with feelings of negative emotions. As such, the qualitative study was also conducted to provide evidence that employees do develop attitudes toward the hospitality industry, and not only toward the specific company they work for, which can be negatively affected by the COVID-19 pandemic. At the time of the data collection, $81.3 \%$ were employed part-time $(58.7 \%)$ or full-time $(22.7 \%)$ in the hospitality industry, the rest identified as not working (i.e., unemployed or furloughed). The participants had an average age of 23.05 and had an average of 3.55 years working in the industry.

The participants responded to two open-ended questions in a survey sent electronically. The first open-ended question asked about their motivation to work in the hospitality industry relative to a specific company. The participants were asked to write down the name of an ideal company they would like to work for, including their current companies, and then answered the first question using this company as a comparison. The second open-ended question asked the extent to which COVID-19 has impacted their motivation to work in the hospitality industry. For both questions, they were asked to explain their answers. 


\subsection{Study 1 qualitative data analysis}

The data was analyzed using a summative content analysis (Hsieh \& Shannon, 2005), which starts with identifying and quantifying target words or content within text with the goal of understanding the participants' thoughts (Hsieh \& Shannon, 2005; Potter \& Levine-Donnerstein, 1999; Yousuf \& Backer, 2015). A summative content analysis was chosen because the qualitative data was used to explore if the COVID-19 pandemic is a stressor affecting the hospitality industry and is associated with feelings of negative emotions; as shown in the first path of the conceptual model (see Figure 1). Therefore, the goal of a summative content analysis is to first identify target words that are commonly used (e.g., "anxious", "stress", "scared") to describe the participants feelings about working in the hospitality industry and how COVID-19 is affecting their careers. Second, a summative content analysis also identifies themes or patterns through latent content analysis. Latent content analysis is the process in which researchers explore the underlying meaning of a target word or the context in which it is used (e.g., anxious about getting sick versus anxious about losing my job) to identify the themes in the data (Hsieh \& Shannon, 2005).

To increase the validity of the coding, the present study involved two steps in the coding process (Shenton, 2004). In the first step, the data were coded by one of the authors. The coding categories and definitions were then given to a second author who independently coded the data. In the second step, both coding schemes were masked and analyzed by the third author and indicated agreement and disagreement across the two coders. A discussion among the coders resolved disagreements on the coding.

\section{Study 1 results}


For the first open-ended question, we quantified how many participants indicated being more motivated to work for the hospitality industry than a specific company. The results showed that $77 \%$ indicated they were more motivated to work for the hospitality industry regardless of a specific company. We then used latent content coding to discover the underlying meaning of their motivation to work for the hospitality industry or a specific company. We developed coding categories inductively and found four major reasons for being motivated to work in the industry (see Table 1 for a summary):

(1) Diverse career opportunities and growth. The respondents provided evidence for the diverse opportunities that the hospitality industry offers. For example, one respondent stated that "I want to work in this industry because it is unique from other industries where it could be paired with other departments like finance, operations, $F \& B$, revenue management, etc." Another said, "I am more motivated to work in the hospitality industry, as a Pastry Chef, because I believe there can be many opportunities from various companies than just one." These exemplars show that employees are motivated to work in the hospitality industry because of its opportunities as opposed to staying at a specific company for their careers.

(2) Enjoying the service environment. The participants also indicated that they enjoy the service environment that is at the heart of the hospitality industry. For example, one respondent indicated they are more motivated to work in the hospitality industry relative to a specific company because "I love working with people, solving people problems, and meeting new people daily," and another respondent said, "I am always passionate in customer services. Creating lasting memories for the guests is the goal I make before starting my shift." These responses suggest that they thrive working in a service environment, regardless of the organization. In other words, the hospitality industry provides workplaces that they enjoy (i.e., service environments). 
(3) Travel opportunities and mobility. The respondents also indicated they are motivated in working in the hospitality industry relative to a specific company because the industry provides travel opportunities and mobility. An exemplar response includes, the "hospitality industry provides more flexibility to move around" and "I'd like working in hospitality, because I like to meet new people, travel and be able to do all sorts of jobs." The responses suggest that employees see the hospitality industry as way to travel, regardless of working for a specific company.

(4) Fitting in the hospitality industry. Lastly, respondents also indicated they are motivated in working in the hospitality industry relative to a specific company because they feel they fit the hospitality industry. For example, "It was always my first career choice to work in this industry since I was little" and "This industry fits my personality and values" are two exemplar responses that reflect their feelings of fitting in the hospitality industry. As such, employees feel that, regardless of a company they work for, they are a good fit for the industry.

For the second open-ended question, we quantified words related how they felt about how COVID-19 has impacted their motivation to work in the hospitality industry. The results showed that "worried" and its synonym "nervous" and "scared" and "fear" were the most commonly used terms to express how they felt about how COVID-19 has impacted their motivation to work in the hospitality industry, which were used by $50 \%$ of the participants. The inductive latent content coding found six major reasons for reactions (see Table 1 for a summary):

(1) The pandemic has impacted the industry negatively. For example, "Seeing how a pandemic affects the lodging industry makes me worried because a lot of people have been laid off" and "It strongly impacted this industry and lots of people are experiencing unemployment" 
reflects that the respondents see COVID-19 as having a direct, negative impact on the hospitality industry. These reactions are aligned with data that shows that the hospitality industry accounted for the majority of the jobs lost during the height of the COVID-19 workplace restrictions orders (US Department of Labor, 2020). The concern over lost jobs due to COVID-19 have also been echoed by the American Hotel and Lodging Association (2020) and National Restaurant Association (2020).

(2) Motivated to work for the hospitality industry. The results also showed that the respondents are motivated to work for the hospitality industry, despite the effects of the pandemic. For example, one respondent said, "This particular pandemic does not sway my thoughts or feelings towards the hospitality industry. It simply reminds me that, like any industry, there will come a time when the environment and its workers are tested." This reflects the motivation that the respondents showed in the answers for the first question. That is, employees are passionate about working for the industry, regardless of a specific company, because of the opportunities and benefits it provides.

(3) The nature of the industry is risky during pandemics. The respondents also suggested that they perceive the nature of the industry (i.e., human interactions) as a risk during pandemics. "It make me feel nervous, because you never which people have this virus" and "I feel nervous because hospitality work involves interacting with people all the time" are two exemplar reactions to how the nature of the industry can be stressful during a pandemic. This also reflects how employees view the hospitality industry, and not only their own job, as a risk during a pandemic.

(4) Worried about the long-term effects. The employees also feel worried about the longterm effects of the pandemic for the future of the industry and their future careers. For example, 
one respondent said, "Anxious and scared right now because who knows how long it will take for the industry to recover." Another said, "Worried, I feel like the hospitality industry will take a lot of time to recover". This theme suggests that the effect of COVID-19 on the industry is making them feel stress and negative emotions. These feelings are likely related to their other reactions, such as the number of lost jobs, the risks of interacting with others, and the uncertainty of when the pandemic will end.

(5) Questioning their careers in the industry. The respondents also suggest that the pandemic has made them question their decision to work in the hospitality industry. For example, one respondent said, "It makes me question my choice of working in the industry very strongly but hopefully the economy will bounce back and people will travel again." Another respondent said, "COVID 19 has me worried about job security in the hospitality industry and whether or not I should be looking for potential backup careers." These responses suggest that employees are feeling stress, anxiety, and other negative emotions because they are now questioning their career choices. COVID-19 has made them re-think their career decisions.

(6) A general feeling of worry. Lastly, the respondents indicated a general feeling of worry, stress, anxiety, and other negative feelings. For example, "It makes me feel very uncertain and nervous" and "I don't feel great. I am nervous and worried" reflect this last theme. These results suggest that employees of the hospitality industry are feeling stress and negative emotions as a result of COVID-19. This theme also reflects the other themes, such as the negative impact on the industry, their questioning of their careers, the stress of feeling risk at work, and the uncertainty of the long-term effects of COVID-19 on the industry.

The respondents' four major reasons for being motivated to work in the industry suggest that they feel industry offers an environment that employees look for, regardless of a company 
they work for. These results provide evidence that employees from the hospitality industry do indeed have reactions, motivations, and feelings toward the hospitality industry and not only toward the specific company they work for. These results from the second open-ended question suggest that they see the COVID-19 pandemic as affecting the industry as a whole, rather than just their own job or a particular company. In addition, the results provide evidence that COVID19 is distressful, as indicated by the negative emotions they used to describe their thoughts. These results showed evidence that (1) the COVID-19 pandemic is perceived as a negative event affecting the industry, rather than only affecting a job or a particular company, and (2) COVID19 is distressful, provoking negative emotions. Thus, as shown in Figure 1, these results suggest that, the COVID-19 pandemic — a negative event — has the potential of affecting employees' attitudes and behaviors toward the hospitality industry, which we tested in Study 2.

\section{Study 2 methodology}

\subsection{Participants \& data collection}

For Study 2, we collected 500 surveys from hospitality industry employees using Mturk. We used several screening items and attention checks. After deleting 21 participants how missed attention check, a total of 479 useable responses (95.8\%) were included in in the subsequent analyses. Additionally, A missing data analysis was conducted to identify the missing data pattern. The results of Littles' test showed that the data was missing completely at random $\left(\operatorname{MCAR} ; \chi^{2}=25.93, d f=23, p>0.05\right.$; Little, 1988). MCAR is a missing data condition in which the likelihood of missingness depends neither on the observed data, nor on the missing data (Dong \& Peng, 2013). When the missing data meet the MCAR assumption, they can be viewed as a random sample of the complete data. Thus, using Listwise deletion to exclude missing data under MCAR will not introduce non-response bias (Dong \& Peng, 2013). After handling missing 
data with Listwise approach, the results are based on 452 employees from the hospitality industry.

To qualify for the study, participants had to be still employed and working, furloughed, or laid off as a result of COVID-19. In regard to employment status, $48.9 \%$ were currently working, and 39.4\% were furloughed, and $11.7 \%$ were laid off as a result of COVID-19 workplace restriction orders; $41.4 \%$ were from hotel and lodging and $58.6 \%$ were from restaurants. The majority were White (59.1\%), male (73\%), supervisor/manager-level employees (75.8\%), paid a salary (74.8\%), and had a 4-year college degree $(60.8 \%)$ or professional degree (21.3\%). The majority were between 25 to 34 (58.4\%) or 35 to 44 (20.8\%) years old. Lastly, the participants reported an average of $6.46(\mathrm{SD}=6.08)$ years working in the hospitality industry.

\subsection{Measures}

Subjective stress. We used the measure developed by Motowidlo et al. (1986).

Participants responded to how much stress they feel because of their current job situation due to COVID-19, so that both employed and furloughed/unemployed employees can respond on a 5point Likert-type scale from strongly disagree to strongly agree $(\alpha=0.78)$.

Negative emotions. We measured negative emotions using Izard's (1991) Differential Emotion Scale III (DES III), which measures five discrete emotions using emotional adjectives and short phrases. They were asked how much they feel these emotions on a daily basis because of their current job situation due to COVID-19. Following the steps by Brown, Westbrook, \& Challagalla (2005), the fifteen items were grouped to measure fear, anger, sadness, guilt, and shame to conduct a hierarchical confirmatory factor analysis (CFA). In this second-order CFA model, the manifest indicators loaded on the discrete emotions, and the five discrete emotions loaded on a composite negative emotion construct. The results of the measurement model 
showed an acceptable model fit $\left(\chi^{2}=136.996, d f=85, p<0.01, \mathrm{CFI}=0.978, \mathrm{TLI}=0.975\right.$, RMSEA $=0.039, \mathrm{SRMR}=0.029)$. Additionally, the range of factor loadings of the five discrete emotions on negative emotions was between 0.75 and 0.86 , indicating sufficient convergence validity. The five discrete emotions were combined into a composite index of negative emotions (Brown et al., 2005); $\alpha=0.94$.

Industry turnover intentions. Turnover intentions by Mowday, Porter, and Steers (1982) was adapted by using industry instead of their company as the target of the items. We used a 5-point Likert-type scale from strongly disagree to strongly agree $(\alpha=0.84)$.

Industry negative word-of-mouth. The measure by Eisingerich et al. (2015) was adapted to indicate the extent to which they would say something negative about working in the hospitality industry using a 5-point Likert-type scale from strongly disagree to strongly agree ( $\alpha$ $=0.85)$.

Control variables. Gender was used as a control variable because research shows gender differences in emotional reaction (Brody \& Hall, 2008). We ran ANOVAs and found no differences between the employment status (still working, furloughed, laid off) on the outcome variables, so they were analyzed as one sample. However, employees laid off because of COVID-19 reported more stress and therefore, employment status (still working, furloughed, laid off) was also used as a covariate.

\section{Study 2 results}

\subsection{Descriptive analysis and measurement model}

Descriptive statistics and correlations are reported in Table 2. Before the hypotheses testing, a CFA was conducted to examine the measurement model fit and the distinctiveness among variables. The four-factor model with stress, industry turnover intentions, industry 
negative word-of-mouth, and negative emotions as a secondary-order measurement demonstrated acceptable model fit: $\chi^{2}=458.956, d f=264, p<0.01, \mathrm{CFI}=0.963$, TLI $=0.956$, RMSEA $=$ $0.051, \mathrm{SRMR}=0.046$ (Kline, 2015). The range of standardized factor loadings of manifest indicators was between 0.72 and 0.94 , and the range of average variance extracted (AVE) for each latent construct was between 0.57 and 0.78 . Kline (2015) indicates that the convergence validity of the measurement model can be achieved when the AVEs of latent variables are above 0.50 . Thus, the results showed that the convergence validity of the measurement model was achieved (Kline, 2015). Additionally, the discriminant validity of the measurement model was examined by comparing the square root of AVE for each construct and its correlation coefficients with other constructs. The square root of AVE for each construct exceeded its correlation coefficient with other constructs, as shown in Table 2, suggesting the acceptable discriminant validity of the measurement model (Kline, 2015).

"The marker variable analysis was used to test the common method bias of the constructs included in the conceptual model following Simmering et al.'s (2015) instruction. Simmering et al. (2015) suggest that an ideal marker variable for common method bias test should share no substantively meaningful variance with the variables suspected of common method bias and have similar to them regarding content and format. Thus, the marker variable should have insignificant correlation with the focal variables and share the same format as the focal variables. Based on Simmering et al.'s (2015) instruction, self-motivation to learn was included in the study as the marker variable. Self-motivation to learn was measured by four items with a 5-point Likert-type scale from strongly disagree to strongly agree, which is consistent with other variables (i.e., 5-point Likert scale). In addition, the Pearson's correlation results showed that the correlations between self-motivation to learn and four focal variables (i.e., 
negative emotions, stress, industry turnover intentions, and industry negative word-of-mouth) were not significant. Therefore, self-motivation to learn is an ideal marker variable to test common method bias. Following Simmering et al. (2015) approach, a Chi-square test was conducted to compare the model fit between unconstrained model and fully constrained model, which specified that there were no factor loadings of manifest indicators on the marker variable. The results showed that the two models were invariant in terms of model fit $\left(\Delta \chi^{2}=20.53, \Delta d f=\right.$ $23, \mathrm{p}=0.61$ ), suggesting common method bias was not an issue in the current study. ---Insert Table 2 here---

\subsection{Hypothesis tests}

The results are demonstrated in Table 3. The control variables, including employees' gender and current employment status, were first entered for all models. The relationship between employees' subjective stress and their industry turnover intentions was significant and positive $(B=0.33, p<0.01)$. The relationship between employees' subjective stress and their industry negative word-of-mouth was significant and positive $(B=0.19, p<0.01)$.

The result showed that subjective stress was significantly related to employees' negative emotions $(B=0.24, p<0.01)$, thereby supporting H1. Additionally, in Model 4 , the relationship between negative emotions and industry turnover intentions was significant after controlling for the effect of subjective stress. Subsequently, the mediating effect of negative emotions on the relationship between subjective stress and industry turnover intentions was examined by the bootstrapping resampling method (Preacher, Rucker, \& Hayes, 2007). Specifically, a 95\% biascorrected bootstrapping confidential interval (CI) was generated to examine the significance of indirect effects. The bootstrapping results showed that the indirect effect of subjective stress on industry turnover intentions via negative emotions was significant (estimate $=0.11, p<0.01 ; \mathrm{CI}$ 
$=[0.05,0.18])$, which supported $\mathrm{H} 2$. In support of $\mathrm{H} 3$, the bootstrapping results indicated that the indirect effect of subjective stress on industry negative word-of-mouth via negative emotions was significant (estimate $=0.17, p<0.01 ; \mathrm{CI}=[0.08,0.26])$. An appendix provides a robustness test to address the potential endogeneity problem in Study 2 (see Appendix B).

\section{Discussion}

\subsection{Theoretical implications}

The first theoretical contribution to the literature on negative work events and stress is that we showed that negative work events that impact entire industries, such as a pandemic, affect employees' attitudes and behaviors toward the industry. Theory and literature on negative work events and stress have mostly focused on how negative events impact employee attitudes and behaviors toward their own organization (e.g., Lee \& Ashforth,1996; Podsakoff et al., 2007; Weiss \& Beal, 2005). Specifically, the current study expands event system theory (Morgeson et al., 2015) to include attitudes and behaviors toward an industry affected by a major negative event. Event system theory (Morgeson et al., 2015) posits that major events, such as pandemics or terrorist attacks, can affect employees directly. However, they limit their implications to organizational-targeted attitudes and behavior. The current paper shows that a negative event, like COVID-19, that impacts an industry harder than others, can relate to negative attitudes and behaviors toward the industry. This is particularly important considering that industries, like the hospitality industry, often rely on a pipeline of employees to maintain an effective workforce (Baum, 2019; Whysall et al., 2019). Both the qualitative (Study 1) and quantitative (Study 2) data revealed that the pandemic has made employees question their decision to work in the hospitality industry. Thus, the current study builds on theory and the literature that has primarily focused on individual organization-related attitudes by showing that major negative events that 
impact the whole industry can also influence employees' attitudes and behaviors towards the industry.

Another theoretical contribution to the literature is that it advances our understanding of how employees process negative work events that impact their industry. The effects of stress and negative emotions on work attitudes have been theorized and widely researched but has mainly focused organization-specific work events as the source of stress. Using the COVID-19 pandemic as the negative work event, the current study builds on Spector and Goh's (2001) model of occupational stress by showing that employees can respond by developing attitudes and behaviors that question their industry as a choice of employment (e.g., industry turnover intentions and industry negative word-of-mouth). Similar to event system theory (Morgeson et al., 2015), Spector and Goh's (2001) model of occupational stress limits the effects of stress to organizational targeted attitudes and behaviors. The current results show how stress and negative emotions associated with COVID-19 relates to attitudes and behaviors toward the hospitality industry, an industry that was impacted by COVID-19 more negatively than others. Stress and affective theories and models (e.g., Ashkanasy \& Dorris, 2017; Lee \& Madera, 2019; Tetrick \& Winslow, 2015; Weiss \& Beal, 2005) mainly focus on the stress and emotional responses to organization-specific events. The current study shows that similar processes occur, from a topdown direction, when dealing with events that affect an industry. In particular, the results from Study 2 showed how subjective stress was related to both industry turnover intentions and negative word-of-mouth, and that these relationships were mediated by negative emotions. These results highlight the important role that negative emotions play in motivating employees to direct attention to reduce distress. We showed that employees can do this by planning to quit working in the industry and negative word-of-mouth. 


\subsection{Practical implications}

The current study also offers practical implications. Many industries, like the hospitality industry, rely on loyal talent who have KSAOs specific to the industry (Bowen \& Ford, 2002), so employees' reactions to a negative work event that impacts their industry are important to understand. The results from Study 1 showed that hospitality employees did perceive the COVID-19 pandemic as a problem for the industry and not only for a specific company, which made them question their future careers in the industry. The results from Study 2 showed that hospitality employees might respond to the stress and negative emotions resulting from the COVID-19 pandemic with industry turnover intentions (i.e., a type of negative attitude toward the industry) and industry negative word-of-mouth (i.e., a type of negative behavior toward the industry). These results suggest that COVID-19 can possibly cause a shortage of employees with loyal talent to leave the industry.

Therefore, even though negative work events such as employees being laid off or furloughed may not be avoidable during the COVID-19 pandemic, it is critical to keep talent in the hospitality industry by reducing their negative emotions through communication. Whereas initial efforts were focused on responding and containing the spread of COVID-19, as businesses, industries, and countries move towards recovering and thriving, the hospitality industry as a whole could help rebuild trust among its employees by communicating what was learned and how it plans to bounce back even stronger. Trade associations and industry partners can also focus recovery efforts on prepare for a "new normal" (Alonso et al., 2020). Specifically, industry trade associations and major corporations that partner with them should communicate plans for recovering lost jobs, plans to address future pandemics, and other negative work events that can affect the industry. For example, to help businesses keep their workforce during the 
COVID-19 crisis, the US small business administration (SBA) will forgive paycheck protection program (PPP) loans if all employees are kept on the payroll for eight weeks (US SBA, 2020). Industry associations should proactively convey information related to relief plans such as PPP loans to hospitality employers and employees and provide guidance for relief plans application. These efforts can reduce employees' negative emotions by providing financial and emotional supports. Similarly, several major associations provided access to free or discounted educational and certificate programs in lieu of workplace restrictions from COVID-19 to help employees increase their hospitality toolkit for when the industry bounces back. In addition, industry associations can provide guidelines for safety measures that organizations can adopt that meets their specific operational needs, such as food handling and safety for restaurants and room cleaning guidelines for hotels. Guidelines for moving forward can potentially serve as signals to employees that their industry is prepared and expecting operations to return. Although layoffs and furloughs were inevitable, the findings of this study suggest employees are loyal to the industry so the hospitality industry and organizations should focus on rebuilding trust with their employees in order to maintain a loyal workforce to aid the recovery and ensure a steady stream of future employees for the industry.

\subsection{Limitations and future research}

The primary limitation of the study is the cross-sectional nature of the data collection. Future research should consider longitudinal study designs that reflect how individuals' reactions to a negative work event, such as the COVID-19 pandemic, can fluctuate over time (Weiss \& Beal, 2005). For example, there might be days in which an employee is feeling more negative emotions leading to a stronger need to cope with their feelings. Another limitation is that we did not consider individual differences that can influence the stress, negative emotions, and industry 
attitude relationship. For instance, employees who are more resilient (Robertson et al., 2015) might experience less stress and negative emotions, resulting in less negative attitudes (e.g., industry turnover intentions) and behaviors (e.g., negative word-of-mouth) toward the industry.

Consistent with past research (e.g., Brown et al., 2015), we used a higher order of negative emotions rather than examining specific emotions related to the industry attitudes. Future research might examine discrete emotions. For example, employees who are still working might feel guilty, because millions of hospitality employees are currently furloughed or laid off, and feeling guilty might be related to other attitudes and behaviors toward the industry. Another limitation is we only measured industry turnover intentions and industry negative word-ofmouth. The qualitative interviews in Study 1, however, revealed that respondents felt a commitment toward working in the hospitality industry, suggesting a need to examine other attitudes and behaviors, such as commitment or loyalty.

Lastly, treating the Covid-19 pandemic as a negative event that causes stress and negative emotions may be an oversimplification. Future research is needed to explain why and how the Covid-19 pandemic, and/or disruptive other events (e.g., terrorist attacks), elicit negative emotions using other theories such as cognitive appraisal theories of emotions as a lens to examine this issue. For example, Lazarus' (1995) cognitive appraisal theory of emotions suggests that appraisal is a critical element for emotional responses to an event or stimuli. Future research might examine appraisals to discover why the Covid-19 pandemic can lead to negative emotions.

\subsection{Conclusion}

The current study examined the effects of stress and negative emotions on employee industry attitudes in response to a negative work event that impacts their industry. The results 
showed that a major negative event, like COVID-19, that impacts an industry more than others is related to subjective stress and negative emotions. Negative emotions, in turn, were related to industry turnover intentions and industry negative word-of-mouth. The current research advances theory and literature on negative work events and stress by underscoring the importance of studying work events that impact an industry, which can result in negative attitudes and behaviors toward the industry. Gaining a better understanding of how employees react to negative work events that impacts their industry can advance knowledge of the role of negative emotions in the stress and work attitudes relationship, and help organizations and industry associations understand how employees react to events that impact their industry. 


\section{References}

Alarcon, G. M. (2011). A meta-analysis of burnout with job demands, resources, and attitudes. Journal of Vocational Behavior, 79(2), 549-562.

Alonso, A. D., Kok, S. K., Bressan, A., O’Shea, M., Sakellarios, N., Koresis, A., ... \& Santoni, L. J. (2020). COVID-19, aftermath, impacts, and hospitality firms: An international perspective. International journal of hospitality management, 91, 102654.

American Hotel Lodging Association (2020). COVID-19's impact on the hotel industry. Retrieved from https://www.ahla.com/covid-19s-impact-hotel-industry.

Ang, S., \& Slaughter, S. (2004). Turnover of information technology professionals: The effects of internal labor market strategies. Database for Advances in Information Systems, 35(3), $11-27$.

Ariza-Montes, A., Arjona-Fuentes, J. M., Han, H., \& Law, R. (2018). Work environment and well-being of different occupational groups in hospitality: Job Demand-Control-Support model. International Journal of Hospitality Management, 73, 1-11.

Arjona-Fuentes, J. M., Ariza-Montes, A., Han, H., \& Law, R. (2019). Silent threat of presenteeism in the hospitality industry: examining individual, organisational and physical/mental health factors. International Journal of Hospitality Management, 82, 191-198.

Ashkanasy, N. M., \& Dorris, A. D. (2017). Emotions in the workplace. Annual Review of Organizational Psychology and Organizational Behavior, 4, 67-90.

Balaji, M. S., Khong, K. W., \& Chong, A. Y. L. (2016). Determinants of negative word-ofmouth communication using social networking sites. Information \& Management, 53(4), 528-540. 
Barello, S. H. (2014). Consumer spending and US employment from the 2007-2009 recession through 2022. Monthly Labor Review, 137, 1-32.

Baum, T. (2019). Does the hospitality industry need or deserve talent?. International Journal of Contemporary Hospitality Management, 31(10), 3823-3837.

Berger, J. (2014). Word of mouth and interpersonal communication: A review and directions for future research. Journal of Consumer Psychology, 24(4), 586-607.

Blomme, R. J., Van Rheede, A., \& Tromp, D. M. (2010). The use of the psychological contract to explain turnover intentions in the hospitality industry: A research study on the impact of gender on the turnover intentions of highly educated employees. The International Journal of Human Resource Management, 21(1), 144-162.

Bowen, J., \& Ford, R. C. (2002). Managing service organizations: Does having a "thing" make a difference?. Journal of Management, 28(3), 447-469.

Brody, L. R., \& Hall, J. A. (2008). Gender and emotion in context. In M. Lewis, J. M. HavilandJones, \& L. F. Barrett (Eds.), Handbook of emotions (p. 395-408). The Guilford Press.

Brown, E. A., Thomas, N. J., \& Bosselman, R. H. (2015). Are they leaving or staying: A qualitative analysis of turnover issues for Generation Y hospitality employees with a hospitality education. International Journal of Hospitality Management, 46, 130-137.

Brown, S. P., Westbrook, R. A., \& Challagalla, G. (2005). Good cope, bad cope: adaptive and maladaptive coping strategies following a critical negative work event. Journal of Applied Psychology, 90(4), 792.

Combs, J., Liu, Y., Hall, A., \& Ketchen, D. (2006). How much do high-performance work practices matter? A meta-analysis of their effects on organizational performance. Personnel psychology, 59(3), 501-528. 
Dawson, M. E. (2014). Preparing students to fit within the hospitality industry culture: Does the educational background make a difference?. Journal of Teaching in Travel \& Tourism, 14(1), 53-68.

Day, A. L., \& Livingstone, H. A. (2001). Chronic and acute stressors among military personnel: do coping styles buffer their negative impact on health?. Journal of occupational health psychology, 6(4), 348.

Dong, Y., \& Peng, C. Y. J. (2013). Principled missing data methods for researchers. SpringerPlus, 2(1), 1-17.

Eisingerich, A. B., Chun, H. H., Liu, Y., Jia, H., \& Bell, S. J. (2015). Why recommend a brand face-to-face but not on Facebook? How word-of-mouth on online social sites differs from traditional word-of-mouth. Journal of Consumer Psychology, 25(1), 120-128.

Fida, R., Paciello, M., Tramontano, C., Fontaine, R. G., Barbaranelli, C., \& Farnese, M. L. (2015). An integrative approach to understanding counterproductive work behavior: The roles of stressors, negative emotions, and moral disengagement. Journal of Business Ethics, 130(1), 131-144.

Field, J., \& Chelliah, J. (2012). Social-media misuse a ticking time-bomb for employers: Robust policies and procedures needed to reduce the risks. Human Resource Management International Digest, 20(7), 36-38.

Fried, Y., Shirom, A., Gilboa, S., \& Cooper, C. L. (2008). The mediating effects of job satisfaction and propensity to leave on role stress-job performance relationships: Combining meta-analysis and structural equation modeling. International Journal of Stress Management, 15, 305-328. 
Garavan, T. N. (2012). Global talent management in science-based firms: an exploratory investigation of the pharmaceutical industry during the global downturn. The International Journal of Human Resource Management, 23(12), 2428-2449.

Geurts, S. A., Schaufeli, W. B., \& Rutte, C. G. (1999). Absenteeism, turnover intention and inequity in the employment relationship. Work \& Stress, 13(3), 253-267.

Golubovskaya, M., Solnet, D., \& Robinson, R. N. (2019). Recalibrating talent management for hospitality: a youth development perspective. International Journal of Contemporary Hospitality Management.

Harris, L. C., \& Ogbonna, E. (2013). Forms of employee negative word-of-mouth: a study of front-line workers. Employee Relations, 35(1), 39-60.

Hsieh, H. F., \& Shannon, S. E. (2005). Three approaches to qualitative content analysis. Qualitative Health Research, 15(9), 1277-1288.

Hult, G. T. M., Hair Jr, J. F., Proksch, D., Sarstedt, M., Pinkwart, A., \& Ringle, C. M. (2018). Addressing endogeneity in international marketing applications of partial least squares structural equation modeling. Journal of International Marketing, 26(3), 1-21.

Izard, C. E. (1991). The psychology of emotions. New York: Plenum Press.

Jung, H. S., \& Yoon, H. H. (2018). Understanding workplace bullying: Its effects on response and behavior in the hospitality industry. International Journal of Contemporary Hospitality Management, 30(3), 1453-1471.

Karabas, I., Joireman, J., \& Kim, S. (2019). Why and when witnessing uncivil behavior leads observers to punish frontline employees and leave the firm. International Journal of Hospitality Management, 82, 91-100. 
Kline, R. B. (2015). Principles and practice of structural equation modeling. Guilford publications.

Laczniak, R. N., DeCarlo, T. E., \& Ramaswami, S. N. (2001). Consumers' responses to negative word-of-mouth communication: An attribution theory perspective. Journal of Consumer Psychology, 11, 57-73.

Lazarus, R. S., \& Folkman, S. (1984). Stress, appraisal, and coping. Springer publishing company.

Little, R. J. (1988). A test of missing completely at random for multivariate data with missing values. Journal of the American Statistical Association, 83(404), 1198-1202.

Lee, L., \& Madera, J. M. (2019). A systematic literature review of emotional labor research from the hospitality and tourism literature. International Journal of Contemporary Hospitality Management, 31(7), 2808-2826.

Lee, L., Guchait, P., \& Madera, J. M. (2020). Negative affect, deep acting, and customer compensation as responses to customer mistreatment: The effect of customer-based perspective-taking. International Journal of Hospitality Management, 89, 102532.

Lee, R. T., \& Ashforth, B. E. (1996). A meta-analytic examination of the correlates of the three dimensions of job burnout. Journal of Applied Psychology, 81(2), 123-133.

Madera, J. M. (2018). When targets blame their organization for sexual harassment: a multilevel investigation of within-person appraisals. Cornell Hospitality Quarterly, 59(1), 49-60.

Makinen, G. (2002). The economic effects of 9/11: a retrospective assessment. Washington, DC: Library of Congress 
Mogg, K., McNamara, J., Powys, M., Rawlinson, H., Seiffer, A., \& Bradley, B. P. (2000). Selective attention to threat: A test of two cognitive models of anxiety. Cognition \& Emotion, 14(3), 375-399.

Morgeson, F. P., Mitchell, T. R., \& Liu, D. (2015). Event system theory: An event-oriented approach to the organizational sciences. Academy of Management Review, 40(4), 515537.

Motowidlo, S. J., Packard, J. S., \& Manning, M. R. (1986). Occupational stress: its causes and consequences for job performance. Journal of Applied Psychology, 71(4), 618.

Mowday, R. T., Porter, L. W., \& Steers, R. (1982). Organizational linkages: The psychology of commitment, absenteeism, and turnover. San Diego, CA: Academic Press

National Restaurant Association (2020). Coronavirus information and resources. Retrieved from https://restaurant.org/Covid19.

National Statistics. (2019). Retrieved from https://www.restaurant.org/research/restaurant$\underline{\text { statistics/restaurant-industry-facts-at-a-glance }}$

Park, J., \& Kim, H. J. (2019). How and when does abusive supervision affect hospitality employees' service sabotage?. International Journal of Hospitality Management, 83, 190-197.

Pennebaker, J. W., Francis, M. E., \& Booth, R. J. (2001). Linguistic inquiry and word count: LIWC 2001. Mahway: Lawrence Erlbaum Associates, 71(2001), 2001.

Pindek, S., Arvan, M. L., \& Spector, P. E. (2019). The stressor-strain relationship in diary studies: A meta-analysis of the within and between levels. Work \& Stress, 33(1), 1-21. 
Podsakoff, N. P., LePine, J. A., \& LePine, M. A. (2007). Differential challenge stressorhindrance stressor relationships with job attitudes, turnover intentions, turnover, and withdrawal behavior: a meta-analysis. Journal of Applied Psychology, 92(2), 438.

Potter,W. J., \& Levine-Donnerstein, D. (1999). Rethinking validity and reliability in content analysis. Journal of Applied Communication Research, 27, 258-284.

Preacher, K. J., Rucker, D. D., \& Hayes, A. F. (2007). Addressing moderated mediation hypotheses: Theory, methods, and prescriptions. Multivariate behavioral research, 42(1), $185-227$

Robertson, I. T., Cooper, C. L., Sarkar, M., \& Curran, T. (2015). Resilience training in the workplace from 2003 to 2014: A systematic review. Journal of Occupational and Organizational Psychology, 88(3), 533-562.

Schmidt, J. A., Willness, C. R., Jones, D. A., \& Bourdage, J. S. (2018). Human resource management practices and voluntary turnover: A study of internal workforce and external labor market contingencies. The International Journal of Human Resource Management, $29(3), 571-594$.

Shenton, A. K. (2004). Strategies for ensuring trustworthiness in qualitative research projects. Education for Information, 22(2), 63-75.

Simmering, M. J., Fuller, C. M., Richardson, H. A., Ocal, Y., \& Atinc, G. M. (2015). Marker variable choice, reporting, and interpretation in the detection of common method variance: A review and demonstration. Organizational Research Methods, 18(3), 473511. 
Spector, P. E., \& Goh, A. (2001). The role of emotions in the occupational stress process. In P. L. Perrewe \& D. C. Ganster (Eds). Research in occupational stress and well-being, Volume 1, pp. 195-232. Greenwich, CT: JAI.

Staufenbiel, T., \& König, C. J. (2010). A model for the effects of job insecurity on performance, turnover intention, and absenteeism. Journal of Occupational and Organizational Psychology, 83(1), 101-117.

Tetrick, L. E., \& Winslow, C. J. (2015). Workplace Stress Management Interventions and Health Promotion. Annual Review of Organizational Psychology and Organizational Behavior, 2, 16-1.

Tongchaiprasit, P., \& Ariyabuddhiphongs, V. (2016). Creativity and turnover intention among hotel chefs: The mediating effects of job satisfaction and job stress. International Journal of Hospitality Management, 55, 33-40.

US Department of Labor (2020). The employment situation: March 2020. Retrieved from https://www.bls.gov/news.release/pdf/empsit.pdf.

US Small Business Administration (2020). Paycheck Protection Program. Retrieved from https://www.sba.gov/funding-programs/loans/coronavirus-relief-options/paycheckprotection-program

Wang, W., Hernandez, I., Newman, D. A., He, J., \& Bian, J. (2016). Twitter analysis: Studying U.S. weekly trends in work stress and emotion. Applied Psychology: An International Review, 65(2), 355-378.

Weiss, H. M., \& Beal, D. J. (2005). Reflections on affective events theory, Ashkanasy, N.M., Zerbe, W.J. and Härtel, C.E.J. (Ed.) The Effect of Affect in Organizational Settings 
(Research on Emotion in Organizations, Vol. 1), Emerald Group Publishing Limited, Bingley, pp. 1-21.

Wetzer, I. M., Zeelenberg, M., \& Pieters, R. (2007). "Never eat in that restaurant, I did!”: Exploring why people engage in negative word-of-mouth communication. Psychology \& Marketing, 24(8), 661-680.

Whysall, Z., Owtram, M., \& Brittain, S. (2019). The new talent management challenges of Industry 4.0. Journal of Management Development, 38(2), 118-129.

Yousuf, M., \& Backer, E. (2015). A content analysis of Visiting Friends and Relatives (VFR) travel research. Journal of Hospitality and Tourism Management, 25, 1-10. 


\section{Table 1}

\section{Qualitative Latent Content Coding Results}

\begin{tabular}{|c|c|}
\hline \multirow{2}{*}{$\begin{array}{l}\text { Question } 1 \text { results } \\
\text { (1) The hospitality industry offers } \\
\text { diverse career opportunities and } \\
\text { growth }\end{array}$} & Exampl \\
\hline & $\begin{array}{l}\text { I am more motivated to keep } \\
\text { working in the industry because } \\
\text { there is more chances of growth. }\end{array}$ \\
\hline & $\begin{array}{l}\text { I would say I am more motivated to } \\
\text { work in events in general in } \\
\text { comparison to a certain } \\
\text { company... but the variety of jobs } \\
\text { in hospitality ensures I will always } \\
\text { be able to find something that } \\
\text { makes me happy. }\end{array}$ \\
\hline $\begin{array}{l}\text { (2) they enjoy the service } \\
\text { environment }\end{array}$ & $\begin{array}{l}\text { I am more motivated to stay } \\
\text { working in the hospitality industry. } \\
\text { I am always passionate in customer } \\
\text { services. Creating lasting memories } \\
\text { for the guests is the goal I make } \\
\text { before starting my shift. }\end{array}$ \\
\hline & $\begin{array}{l}\text { In the hospitality industry. I love } \\
\text { working around people and giving } \\
\text { service. }\end{array}$ \\
\hline
\end{tabular}

(3) travel opportunities and mobility in the hospitality industry

4) feeling of fitting in the hospitality industry
I'd like working in hospitality, because I like to meet new people, travel and be able to do all sorts of jobs.

Hospitality industry because it appeals to me, and I like to travel and help people.

...this industry fits my personality and values.

...it was always my first career choice to work in this industry since I was little.

\section{quotes}

I am more motivated to work in the hospitality industry, as a Pastry Chef, because I believe there can be many opportunities from various companies than just one.

I want to work in this industry because it is unique from other industries where it could be paired with other departments like finance, operations, $F \& B$, revenue management, etc.

The industry, because I feel that I enjoy the service environment.

The hospitality industry, because I love working with people, solving people problems, and meeting new people daily.

The hospitality industry, because I love to travel so I would like to be around something I like to do.

Hospitality industry provides more flexibility to move around.

The hospitality industry has always been a part of my life which is why I am motivated to work in this specific industry.

Yes, this industry fits me well... 
(1) the pandemic has impacted the industry negatively

(2) they still are motivated to work for the hospitality industry, despite the effects of the pandemic
There is a huge impact on the hospitality industry, it's unstable, but I still want to work in this industry, but still need to learn some skills about other industry to prepare, in case I lose my job.

It strongly impacted this industry and lots of people are experiencing unemployment.

I still want to work in this industry, but when the Covid-19 happened it affected the hospitality industry.
(3) they perceive the nature of the industry (i.e., human interactions) as a risk during pandemics
(4) worried about the long-term effects of the pandemic for the future of the industry and their future careers
Since I plan to move into events, my view is slightly different but I do have some worries going into this field due to the decrease in job opportunities. Regardless, I am still motivated to stay this industry.

My workplace is a restaurant, and I am still being employed. Even though we've been doing take-out order, it is still risky as you still need to face customer and coworkers, who still works under same place with you.

A lot of people are in danger with so much contact. I wanted to go into events or weddings but this pandemic is making that impossible.

COVID-19 makes me change my mind about the working place in future...

Worried, I feel like the hospitality industry will take a lot of time to recover.
Seeing how a pandemic affects the lodging industry makes me worried because a lot of people have been laid off.

COVID-19 put into perspective just how quickly things can turn around and how different the hospitality industry is from others.

With the COVID-19 situation going on, the hospitality and tourism industry has dropped tremendously, and when things pick back up I would like to help as much as I can and be safe and clean, trying to make a big impact on the industry.

This particular pandemic does not sway my thoughts or feelings towards the hospitality industry. It simply reminds me that, like any industry, there will come a time when the environment and its workers are tested.

It makes me feel nervous, because you never which people have this virus.

I feel nervous because hospitality work involves interacting with people all the time.

Anxious and scared right now because who knows how long it will take for the industry to recover.

COVID-19 has made me really nervous about choosing a career path in the hospitality industry. The industry is taking a huge hit and I'm incredibly unsure about whether or 
Table 2

Means, Standard Deviation, and Correlations

\begin{tabular}{|c|c|c|c|c|c|c|c|c|}
\hline & Mean & $S D$ & 1 & 2 & 3 & 4 & 5 & 6 \\
\hline 1.Gender & 1.26 & 0.44 & & & & & & \\
\hline 2. Employment status & 1.51 & 0.50 & $0.16^{* *}$ & & & & & \\
\hline 3. Subjective stress & 3.53 & 0.88 & $0.10^{*}$ & $0.19^{* *}$ & 0.75 & & & \\
\hline 4. Negative emotion & 3.12 & 0.98 & $-0.13^{* *}$ & 0.00 & $0.19^{* *}$ & 0.88 & & \\
\hline 5. Industry turnover intention & 3.41 & 1.09 & $-0.10^{*}$ & 0.06 & $0.27^{* *}$ & $0.46^{* *}$ & 0.80 & \\
\hline 6. Industry negative word-of-mouth & 3.06 & 1.19 & $-0.18^{* *}$ & -0.04 & $0.12^{* *}$ & $0.60^{* *}$ & $0.59^{* *}$ & $\mathbf{0 . 8 2}$ \\
\hline
\end{tabular}

Note. $N=452 . \mathrm{SD}=$ standard deviation. Gender was dummy coded $1=$ male $2=$ female. Employment status: $1=$ still working $2=$ furloughed or laid off. ${ }^{*} p<$

$0.05, \stackrel{* *}{p}<0.01$. Bold figures on the diagonal are the square root of the average variance extracted (AVE) for each construct. 


\section{Table 3}

Regression Results for Hypothesized Relationships

\begin{tabular}{|c|c|c|c|c|c|c|c|c|c|c|}
\hline \multirow[b]{3}{*}{ Predictors } & \multirow{2}{*}{\multicolumn{2}{|c|}{$\begin{array}{c}\text { Negative Emotion } \\
\text { Model } 3 \\
\text { Hypothesis } 3 \\
\end{array}$}} & \multicolumn{4}{|c|}{ Industry turnover intentions } & \multicolumn{4}{|c|}{ Industry negative WoM } \\
\hline & & & \multicolumn{2}{|c|}{$\begin{array}{c}\text { Model } 1 \\
\text { Hypothesis } 1 \\
\end{array}$} & \multicolumn{2}{|c|}{$\begin{array}{c}\text { Model4 } \\
\text { Hypothesis } 4\end{array}$} & \multicolumn{2}{|c|}{$\begin{array}{c}\text { Model } 2 \\
\text { Hypothesis } 2 \\
\end{array}$} & \multicolumn{2}{|c|}{$\begin{array}{c}\text { Model } 5 \\
\text { Hypothesis } 5 \\
\end{array}$} \\
\hline & Estimate & $S E$ & Estimate & $S E$ & Estimate & $S E$ & Estimate & $S E$ & Estimate & $S E$ \\
\hline Intercept & $2.74^{* *}$ & 0.24 & $2.59^{* *}$ & 0.26 & $1.31^{* *}$ & 0.27 & $3.16^{* *}$ & 0.29 & $1.21^{* *}$ & 0.27 \\
\hline Control variable & & & & & & & & & & \\
\hline Gender & $-0.32^{* *}$ & 0.10 & $-0.33^{*}$ & 0.12 & -0.18 & 0.11 & $-0.49^{* *}$ & 0.13 & $-0.26^{*}$ & 0.10 \\
\hline Employment status & -0.05 & 0.09 & 0.04 & 0.10 & 0.06 & 0.10 & -0.12 & 0.11 & -0.08 & 0.09 \\
\hline Direct effect & & & & & & & & & & \\
\hline $\begin{array}{l}\text { Subjective stress } \\
\text { Negative emotion }\end{array}$ & $0.24^{* *}$ & 0.05 & $0.33^{* *}$ & 0.06 & $\begin{array}{l}0.22^{* *} \\
0.47^{* *}\end{array}$ & $\begin{array}{l}0.06 \\
0.05\end{array}$ & $0.19^{* *}$ & 0.06 & $\begin{array}{c}0.02 \\
0.71^{* *} \\
\end{array}$ & $\begin{array}{l}0.05 \\
0.04\end{array}$ \\
\hline
\end{tabular}

Note: $N=452 . S E$ : standard error. Industry negative WoM: industry negative word-of-mouth. Gender was dummy coded $1=$ male $2=$ female. Employment status: $1=$ still working 2 = furloughed or laid off. $* p<0.05, * * p<0.01$ 


\section{Figure 1}

\section{Conceptual Model}

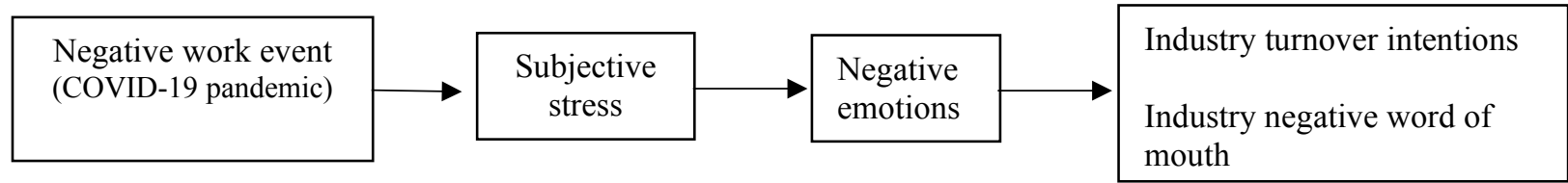


Appendix A. Scale Properties and Results of CFA

\begin{tabular}{clrr}
\hline Scale & Item & Loading & Std. err \\
\hline Scared & & & \\
& Indicate the extent to which you experienced each of these feelings at the time \\
& when you learned how your job has been affected by COVID-19 & \\
SC1 & Fearful & $0.80^{* *}$ & 0.02 \\
SC2 & Afraid & $0.79^{* *}$ & 0.02 \\
SC3 & Scared & $0.79^{* *}$ & 0.02 \\
Anger & & & \\
& Indicate the extent to which you experienced each of these feelings at the time \\
& when you learned how your job has been affected by COVID-19 & \\
ANG1 & Angry & $0.82^{* *}$ & 0.02 \\
ANG2 & Mad & $0.79^{* *}$ & 0.02 \\
ANG3 & Enraged & $0.78^{* *}$ & 0.02
\end{tabular}

Sadness
SAD1
SAD2 Sad
$0.79^{* *}$
0.03
SAD3 Discouraged
$0.81^{* *} \quad 0.02$

Indicate the extent to which you experienced each of these feelings at the time when you learned how your job has been affected by COVID-19

Guilt

Indicate the extent to which you experienced each of these feelings at the time when you learned how your job has been affected by COVID-19
GUI1 Guilty
$0.82^{* *} \quad 0.02$
GUI2 Repentant
$0.82^{* *} \quad 0.02$
GUI3 Blameworthy
$0.85^{* *} \quad 0.02$

Shame

Indicate the extent to which you experienced each of these feelings at the time when you learned how your job has been affected by COVID-19

$\begin{array}{lllr}\text { SHA1 } & \text { Shame } & 0.83^{* *} & 0.02 \\ \text { SHA2 } & \text { Bashful } & 0.85^{* *} & 0.02 \\ \text { SHA3 } & \text { Shy } & 0.86^{* *} & 0.02 \\ \text { Negative emotions } & & \\ \text { SC } & & 0.84^{* *} & 0.03 \\ \text { ANG } & & 0.94^{* *} & 0.02 \\ \text { SAD } & & 0.87^{* *} & 0.03 \\ \text { GUI } & & 0.92^{* *} & 0.03 \\ \text { SHA } & & 0.85^{* *} & 0.03 \\ \text { tress } & \text { I feel a great deal of stress because of my current job } & 0.72^{* *} & 0.04 \\ \text { STR1 } & & \\ & \text { situation. } & 0.79^{* *} & 0.04 \\ \text { STR2 } & \text { Very stressful things happen to me because of my current } & & \\ & \text { job situation } & 0.75^{* *} & 0.04 \\ \text { STR3 } & \text { My current job situation is extremely stressful. } & \end{array}$
Industry turnover intentions 
ITI1 You think a lot about leaving this industry. $\quad 0.81^{* *} \quad 0.02$

ITI2 You are actively searching for an alternative to this $\quad 0.75^{* *} \quad 0.03$ industry.

ITI3 As soon as it is possible, you will leave this industry. $\quad 0.83^{* *} \quad 0.02$ Industry negative word-of-mouth

$\begin{array}{llll}\text { WOM1 I will say negative things about the industry to others. } & 0.86^{* *} & 0.02\end{array}$

WOM2 I will discourage friends and relatives to work in this $\quad 0.80^{* *} \quad 0.02$

$\begin{array}{llll} & \text { industry } & & \\ \text { WOM3 } & \text { I will NOT recommend this industry to others. } & 0.79^{* *} & 0.02\end{array}$

Note: $* *: p<.01, *: p<.05 ; \mathrm{SC}=$ scared, $\mathrm{ANG}=$ anger, $\mathrm{SAD}=$ sadness, $\mathrm{GUI}=$ guilt, $\mathrm{SHA}=$ shame, $\mathrm{STR}=$ stress, $\mathrm{ITI}=$ industry turnover intentions, WOM $=$ industry negative word-of-month. 


\section{Appendix B. Robustness Test}

Because stress and negative emotions are both subjective responses to negative events (Spector \& Goh, 2001), it is necessary to test the potential endogeneity problem in the present study. Thus, following Hult et al. (2018) method, the current study conducted structure equation modeling (SEM) analyses to compare the model fit of our proposed model and a comparative model with negative emotions as the predictor and stress as the mediator between the effects of negative emotion on turnover intentions and negative word-of-mouth.

The model fit indexes of the proposal model with negative emotions as the mediator showed a good fit: $\chi^{2}=706.615, d f=221, p<0.01, \mathrm{CFI}=0.947, \mathrm{TLI}=0.936, \mathrm{RMSEA}=0.060$, SRMR $=0.063$ (Kline, 2015). The mediation test with SEM approach showed a consistent result with the regression-based approach in the main analysis such that the indirect effects of subjective stress on industry turnover intentions (estimate $=0.11, p<0.01 ; \mathrm{CI}=[0.05,0.19])$ and industry negative word-of-mouth (estimate $=0.17, p<0.01 ; \mathrm{CI}=[0.08,0.26]$ ) via negative emotions were significant. In addition, model fit of the comparative model with the subjective stress as the mediator was significant worse than the proposed model $\left(\Delta \chi^{2}=99.64, \Delta \mathrm{CFI}=0.04\right.$, $\triangle \mathrm{RSMEA}=0.02)$. Thus, the results of the robustness test supported the hypothesized mediation model and suggested that endogeneity was not an issue in the current study (Hult et al., 2018). 